\title{
ATP Controls Neuronal Apoptosis Triggered by Microtubule Breakdown or Potassium Deprivation
}

\author{
Christiane Volbracht, Marcel Leist, and Pierluigi Nicotera \\ Faculty of Biology, Department of Molecular Toxicology, University \\ of Konstanz, Konstanz, Germany
}

Accepted May 30, 1999.

\begin{abstract}
Background: Early loss of neurites followed by delayed damage of neuronal somata is a feature of several neurodegenerative diseases. Death by apoptosis would ensure the rapid removal of injured neurons, whereas conditions that prevent apoptosis may facilitate the persistence of damaged cells and favor inflammation and disease progression.

Materials and Methods: Cultures of cerebellar granule cells (CGC) were treated with microtubule disrupting agents. These compounds induced an early degeneration of neurites followed by apoptotic destruction of neuronal somata. The fate of injured neurons was followed after co-exposure to caspase inhibitors or agents that decrease intracellular ATP (deoxyglucose, $S$-nitrosoglutathione, 1-methyl-4-phenylpyridinium). We examined the implications of energy loss for caspase activation, exposure of phagocytosis markers, and long-term persistence of damaged cells.
\end{abstract}

Results: In CGC exposed to colchicine or nocodazole,

axodendritic degeneration preceded caspase activation and apoptosis. ATP-depleting agents or protein synthesis inhibition prevented caspase activation, translocation of the phagocytosis marker, phosphatidylserine, and apoptotic death. However, they did not affect the primary neurite loss. Repletion of ATP by enhanced glycolysis restored all apoptotic features. Peptide inhibitors of caspases also prevented the apoptotic changes in the cell bodies, although the axodendritic net was lost. Under this condition cell demise still occurred $48 \mathrm{hr}$ later in a caspase-independent manner and involved plasma membrane lysis at the latest stage.

Conclusions: Inhibition of the apoptotic machinery by drugs, energy deprivation, or endogenous mediators may result in the persistence and subsequent lysis of injured neurons. In vivo, this may favor the onset of inflammatory processes and perpetuate neurodegeneration.

\section{Introduction}

Apoptosis is a mode of cell death by which superfluous or dysfunctional cells are removed from tissues. However, an increased rate of apoptosis may also be a component of neurodegenerative diseases $(1,2)$. Frequently, the apoptotic execution phase is characterized by activation of caspases that cleave a defined subset of cellular

Address correspondence and reprint requests to: Prof. P. Nicotera, Chair of Molecular Toxicology, Faculty of Biology, University of Konstanz, Box X911, D-78457 Konstanz, Germany. Phone: 49-7531-884035; Fax: 49-7531-884033; E-mail: pierluigi.nicotera@uni-konstanz.de proteins (3). This leads to characteristic morphological changes such as nuclear condensation (4), and to the display of phagocytosis recognition molecules on the cell surface $(5,6)$. The latter process is responsible for the swift removal of dying cells before the plasma membrane lyses (7). Rapid and efficient phagocytosis may also explain the low frequency of apoptotic cells, which can be observed in neurodegenerative disorders $(1,8,9)$. In fact, in Alzheimer's disease, the persistence of dysfunctional (10) and degenerating neurons is more conspicuous than apoptosis (11). Neurons initially undergo cytoskeletal 
changes and lose dendritic projections, until only the cell bodies seem to be left at late stages. Similar changes are common to several axonopathies (11).

The persistence of neuronal remnants in such conditions may be explained by a block or low efficiency of the mechanisms that lead to the activation of the protease families (primarily caspases) involved in exposure of recognition molecules. This would result in a defective disposal of dying cells (5-7). It has been shown that the activation of caspases by the cytochrome-c and Apaf-1-containing apoptosome requires dATP or ATP $(12,13)$. Thus, severe disorders in energy metabolism may preclude the activation of caspases. In agreement with this is the finding that apoptosis of tumor cells is entirely suppressed when cellular ATP is depleted by $50-$ $60 \%(14,15)$. Also, in neurons, there is circumstancial evidence for a similar control of cell death by ATP: in cultures exposed to glutamate (16) or 1-methyl-4-phenylpyridinium $\left(\mathrm{MPP}^{+}\right)$ (17), only the neuronal subpopulation that maintains an adequate cellular energy charge dies with apoptotic features.

Thus, we designed this study to test whether manipulation of neuronal ATP levels by drugs or mediators, which affect energy metabolism, would compromise the execution and occurrence of cell death following an initial axonal degeneration. Cell death was triggered in cerebellar granule neurons (CGC) by the cytoskeletal disrupting agents colchicine or nocodazole, which are known to trigger caspase activation (18) and delayed neuronal apoptosis both in vivo and in vitro $(19,20)$. Finally, we examined the long-term fate of neurons that were treated with microtubule poisons but were incapable of executing apoptosis because of caspase inhibition.

\section{Materials and Methods}

\section{Materials}

SYTOX and H-33342 were obtained from Molecular Probes (Eugene, OR). The caspase substrate, $\mathrm{N}$-acetyl-Asp-Glu-Val-aspartyl-aminotrifluoromethylcoumarine (DEVD-afc), 1-methyl-4phenyl-pyridinium $\left(\mathrm{MPP}^{+}\right)$, cyclosporine $\mathrm{A}$ (CsA), and $S$-nitrosoglutathione (GSNO) were obtained from Biomol (Hamburg, Germany), and (+)-5methyl-10,1 1-dihydro-5H-dibenzo[a,d]cyclohepten-5,10-imine (MK801) came from RBI (Biotrend Chemikalien GmbH, Köln, Germany). Caspase inhibitors $N$-acetyl-Asp-Glu-Val-Asp- aldehyde (DEVD-CHO), $N$-benzyloxycarbonylVal-Ala-aspartyl-fluoromethylketone (zVAD-fmk), $N$-acetly-Tyr-Val-Ala-aspartyl-chloromethylketone (YVAD-cmk), and $N$-benzyloxycarbonylaspartyl-2,6-dichlorobenzoyloxymethylketone (ZD-cbk) were obtained from Bachem Biochemica GmbH (Heidelberg, Germany). DEVD-fmk was from Enzyme Systems (Dublin, CA). Fluoresceinlabeled annexin V (annexin V) was from Boehringer-Mannheim (Mannheim, Germany). FK506 came from Alexis (Grünberg, Germany), and $\mathrm{L}-\left[4,5-{ }^{3} \mathrm{H}\right]$-leucine was from AmershamBuchler (Braunschweig, Germany). Solvents and inorganic salts were from Merck (Darmstadt, Germany) or Riedel-de Haen (Seelze, Germany). All other reagents not further specified were from Sigma (Deisenhofen, Germany).

\section{Animals}

Eight-day-old specific, pathogen-free BALB/c mice were obtained from the Animal Unit of the University of Konstanz. All experiments were performed in accordance with international guidelines to minimize pain and discomfort $(\mathrm{NIH}$ guidelines and European Community Council Directive 86/609/EEC).

\section{Cell Culture}

Murine CGC were chosen for these studies and isolated as described previously (21). These cells form a highly complex axodendritic network consisting of over $95 \%$ of one single neuronal type. Dissociated neurons were plated on 100 $\mu \mathrm{g} / \mathrm{ml}(250 \mu \mathrm{g} / \mathrm{ml}$ for glass surfaces) poly-L-lysine ( $\mathrm{MW}>300 \mathrm{kDa}$ ) coated dishes at a density of about $0.25 \times 10^{6}$ cells $/ \mathrm{cm}^{2}(800,000$ cells $/ \mathrm{ml}$; $500 \mu \mathrm{l} /$ well, 24-well plate) and cultured in Eagle's basal medium (BME, Gibco) supplemented with $10 \%$ heat inactivated fetal calf serum (FCS), $20 \mathrm{mM} \mathrm{KCl}, 2 \mathrm{mM}$ L-glutamine and penicillinstreptomycin, and cytosine arabinoside (added $48 \mathrm{hr}$ after plating). Neurons were used without further medium changes after 8 days in vitro (DIV). At that time, the residual glucose concentration in the medium was about $1 \mathrm{mM}$. The cultures were exposed to colchicine or nocodazol in their original medium for most experiments in the presence of $2 \mu \mathrm{M} \mathrm{MK} 80 \mathrm{l}$ and $2 \mathrm{mM} \mathrm{Mg}^{2+}$ to prevent NMDA receptor activation and excitotoxicity (22). All inhibitors were added $30 \mathrm{~min}$ before the microtubule disrupters, unless stated otherwise. 
ATP Depletion Experiments and Repletion with Glucose

In initial experiments, the ATP depletors [deoxyglucose (DG), MPP ${ }^{+}$, or GSNO] were added 30 min before colchicine exposure and remained present throughout the experiment. To restore ATP, the culture medium was supplemented with glucose ( 0 or $10 \mathrm{mM}$ ) $3 \mathrm{hr}$ before exposure to colchicine. In this setup, the ATP depletors were added $8 \mathrm{hr}$ after colchicine addition. Measurements of ATP and of protein synthesis (leucine-incorporation) were performed after 9.5 hr. Apoptosis and caspase activity were quantitated after $18 \mathrm{hr}$. In some delayed ATP repletion experiments, colchicine-treated CGC were kept ATP-deprived by deoxyglucose for $20 \mathrm{hr}$. After that time glucose (10 mM) was added and nuclear condensation was followed over the following $4 \mathrm{hr}$.

\section{ATP Repletion with Alternative Energy Substrates}

To test alternative energy substrates that would not increase the cellular capacity to generate NADPH via the pentose-phosphate shunt, cells were incubated with deoxyglucose plus succinate, glutamine, glycerol, or several other substrates. Colchicine was added $60 \mathrm{~min}$ after the energy substrates. ATP was determined after 10 $\mathrm{hr}$ and apoptosis after $16 \mathrm{hr}$.

\section{Viability Assays}

Apoptosis and secondary lysis were routinely quantified by double staining of neuronal cultures with $1 \mu \mathrm{g} / \mathrm{ml} \mathrm{H}$-33342 (membrane permeant, blue-fluorescent chromatin stain) and $0.5 \mu \mathrm{M}$ SYTOX (non-membrane permeant, green-fluorescent chromatin stain) as described previously (23). Apoptotic cells were characterized by scoring typically condensed nuclei. About 600-1000 cells were counted in nine different fields in 2-3 different culture wells, and experiments were repeated in at least three different preparations. In addition, the percentage of viable cells was quantified by their capacity to reduce 3-(4,5-dimethylthiazole-2-yl)-2,5-diphenyltetrasodium bromide (MTT) after incubation with $0.5 \mathrm{mg} / \mathrm{ml}$ MTT for $60 \mathrm{~min}$. As an additional parameter to assess plasma membrane integrity, CGC were loaded with $0.5 \mu \mathrm{M}$ calcein-AM for 5 min (23). Oligonucleosomal DNA fragmentation was quantified as described before by an ELISA method (24).

\section{Immunocytochemistry}

CGC were grown on glass-bottomed culture dishes, fixed after the experiment with $4 \%$ paraformadehyde, and permeabilized with $0.1 \%$ Triton X-100 in phosphate-buffered saline (PBS). To monitor cytoskeletal alterations, we stained neurons with an anti- $\beta$ III tubulin monoclonal antibody (1:300, \#clone5G8, Promega, Mannheim, Germany), which recognizes only neuronal tubulin, as described previously (20). As secondary antibody, we used an Alexa $\left(\lambda_{\mathrm{ex}}=488\right.$ $\mathrm{nm}, \lambda_{\mathrm{em}}=512 \mathrm{~nm}$ ) coupled anti-mouse IgG antibody (1:300, Molecular Probes). CGC were embedded in PBS containing 50\% glycerol and $0.5 \mu \mathrm{g} / \mathrm{ml} \mathrm{H}-33342$ and imaged by confocal microscopy (TCS-4D UV/VIS confocal scanning system; Leica AG, Benzheim and Leica Lasertechnik, Heidelberg, Germany).

\section{Protein Synthesis}

Protein synthesis was analyzed as described previously (25). Briefly, ${ }^{3} \mathrm{H}$-leucine $(2 \mu \mathrm{Ci})$ was added to CGC in a volume of $10 \mu \mathrm{l}$, in 24-well plates (150 MBq/ml final). After $90 \mathrm{~min}$ incubation, the medium was removed. Cells were washed three times with ice-cold trichloroacetic acid (TCA, 10\%) and dried with methanol $\left(-20^{\circ} \mathrm{C}\right)$. The cell layers were lysed $(0.3 \mathrm{M}$ $\mathrm{NaOH}, 1 \% \mathrm{SDS}$ ) for $12 \mathrm{hr}$ at $37^{\circ} \mathrm{C}$, and incorporated radioactivity was detected by $\beta$-scintillation counting.

\section{Visualization of Phosphatidylserine Translocation}

Surface phosphatidylserine expression of cultures grown on glass-bottomed culture dishes was analysed by annexin V staining and confocal microscopy (TCS-4D UV/VIS confocal scanning system; Leica AG and Leica Lasertechnik) as described previously (18).

\section{Enzymatic Assays}

Caspase-3-like activity (measured by DEVD-afc cleavage) was assayed essentially as described before $(26,27)$. CGC were lysed in $25 \mathrm{mM}$ HEPES, 5 $\mathrm{mM} \mathrm{MgCl}_{2}, 1 \mathrm{mM}$ EGTA, 0.5\% Triton X-100, 1 $\mu \mathrm{g} / \mathrm{ml}$ leupeptin, $1 \mu \mathrm{g} / \mathrm{ml}$ pepstatin, $1 \mu \mathrm{g} / \mathrm{ml}$ aprotinin, and $1 \mathrm{mM}$ PEFA-block, $\mathrm{pH}$ 7.5. The fluorimetric assay was carried out in microtiter plates with a substrate concentration of $40 \mu \mathrm{M}$ and a total protein amount of $5 \mu \mathrm{g}$. Glucose concentrations in the medium were determined by the hexokinase/ glucose dehydrogenase method using a commer- 
cial kit (Sigma). ATP was measured luminometrically after lysis of cells in ATP-releasing agent (Sigma) as described earlier $(14,22)$. Total cellular glutathione was determined according to the enzymatic cycling method of Tietze (28). Briefly, cells grown in 12-well plates were lysed at different times with cold $0.1 \mathrm{mM} \mathrm{HCl} / 10 \mathrm{mM}$ EDTA and immediately frozen. After thawing, glutathione was determined from the supernatant by an automated enzymatic analyzer (ACP5040, Eppendorff, Hamburg, Germany). Control cells had a glutathione content of $420 \pm 20 \mathrm{pmol} / 10^{6}$ neurons.

\section{Western Blot Analysis}

CGC were lysed in RIPA buffer $(150 \mathrm{mM} \mathrm{NaCl}$, $50 \mathrm{mM}$ Tris, $1 \%$ NP-40, $0.25 \%$ sodium deoxycholate, 1 mM EGTA) supplemented with protease inhibitors [l $\mathrm{mM}$ phenylmethylsulfonyl fluoride (PMSF), $1 \mathrm{mM}$ benzamidine, $1 \mathrm{mM}$ iodoacetate, $1 \mathrm{mM}$ iodoacetamide, $40 \mu \mathrm{M}$ leupeptin, $10 \mu \mathrm{g} / \mathrm{ml}$ antipain, $5 \mu \mathrm{g} / \mathrm{ml}$ pepstatin]. Protein was determined using the bicinchoninic acid method (Bio-Rad, München, Germany).

Proteins were separated by SDS-PAGE with $5 \mu \mathrm{g}$ protein/lane on $8 \%$ polyacrylamide gels for fodrin, and $80 \mu \mathrm{g}$ protein/lane on $4-20 \%$ polyacrylamide gradient gels for caspase-3/-7, and then blotted onto nitrocellulose membranes (Amersham-Buchler) in a Bio-Rad semidry blotter at $2.5 \mathrm{~mA} / \mathrm{cm}^{2}$ for $60 \mathrm{~min}$. Blots were blocked in TNT $(50 \mathrm{mM}$ Tris $\mathrm{pH} 8.0,150 \mathrm{mM} \mathrm{NaCl}$, $0.05 \%$ Tween 20 ) containing $5 \%$ dried milk/1\% bovine serum albumin (BSA) and then incubated with either anti-fodrin monoclonal antibody (1:500, clone \#1622, Chemicon, Temecula, CA), or anti-caspase-3 pl7 polyclonal antibody (1:1000, R\#MF393, generously provided by Dr. D. W. Nicholson, Merck-Frost, Quebec, Canada) or anti-caspase-7, pl7 polyclonal antibody (1: 1000 , \#R151, generously provided by Dr. G. Cohen, MRC Toxicology Unit, Leicester, UK). Specifically stained bands were detected by chemiluminescence (ECL, Amersham) using a polyclonal IgG horseradish peroxidase-coupled secondary antibody (1:1000, Pharmingen). As a positive control for caspase- 3 detection, we used recombinant caspase-3 (generously provided by Dr. F. Fackelmayer, Department of Biology, University of Konstanz, Germany), which appeared as a $29 \mathrm{kDa}$ band after isolation from bacterial lysates and which was processed autocatalytically by about $90 \%$ [ $17 \mathrm{kDa}$ band; specific activity $70 \times 10^{6} \mathrm{pmol} /(\mathrm{min} \times \mathrm{mg}$ protein $\left.)\right]$.

\section{Statistics}

Experiments to determine cell viability, ATP, protein synthesis, or caspase activity were run as triplicates and repeated in three- to eight-cell preparations. Statistical significance was calculated on the original data sets by means of the Student's $t$-test. When variances within the compared groups were not homogeneous the Welch test was applied. All Western blots were performed with samples from at least three independent cell preparations.

\section{Results}

Caspase Activation following Microtubule Disruption in Neurons

To depolymerize neuronal microtubules, we used the two chemically unrelated drugs-colchicine $(1 \mu \mathrm{M})$ and nocodazol $(1 \mu \mathrm{M})\left(\mathrm{EC}_{50}\right.$ of both drugs: $50-100 \mathrm{nM}$ ). The first alterations of CGC microtubule network became apparent $6 \mathrm{hr}$ after exposure to colchicine or nocodazol in the axodendritic net. After $12 \mathrm{hr}$, while nuclear morphology was still normal (Fig. 1A), the microtubule organization was severely compromised, and the activity of caspase-3-related caspases (DEVD-afc cleavage activity) started to increase (Fig. 1B). At the same time, the processing of procaspase-3 (Fig. 1C) and procaspase-7 (not shown) was evident on Western blots. After 15 $\mathrm{hr}$, the microtubule network was completely lost, leaving only a small ring enveloping the nucleus (Fig. 2). Meanwhile, caspase activity had greatly increased and a large percentage of nuclei displayed apoptotic chromatin condensation and fragmentation. Between 18 and $24 \mathrm{hr}$ after the exposure to either of the two microtubule disrupters, the increase in caspase activity reached a maximum (40- to 60-fold compared to control neurons), oligonucleosomal DNA fragmentation was increased 25- to 30 -fold, and the percentage of apoptotic neurons reached a maximum of about $80 \%$.

To examine whether caspase activation by colchicine and nocodazol was entirely due to microtubule depolymerization, we used taxol, a drug that stabilizes microtubules and antagonizes the effects of colchicine (20) and nocodazole. Treatment of CGC with $1 \mu \mathrm{M}$ taxol up to $3 \mathrm{hr}$ after colchicine addition prevented both microtubule breakdown and the increase in caspase activity (Fig. 2). In contrast, pharmacological inhibitors of the $N$-methyl-D-aspartate (NMDA) receptor (2 $\mu \mathrm{M} \mathrm{MK} 801$ ), of voltage-dependent 


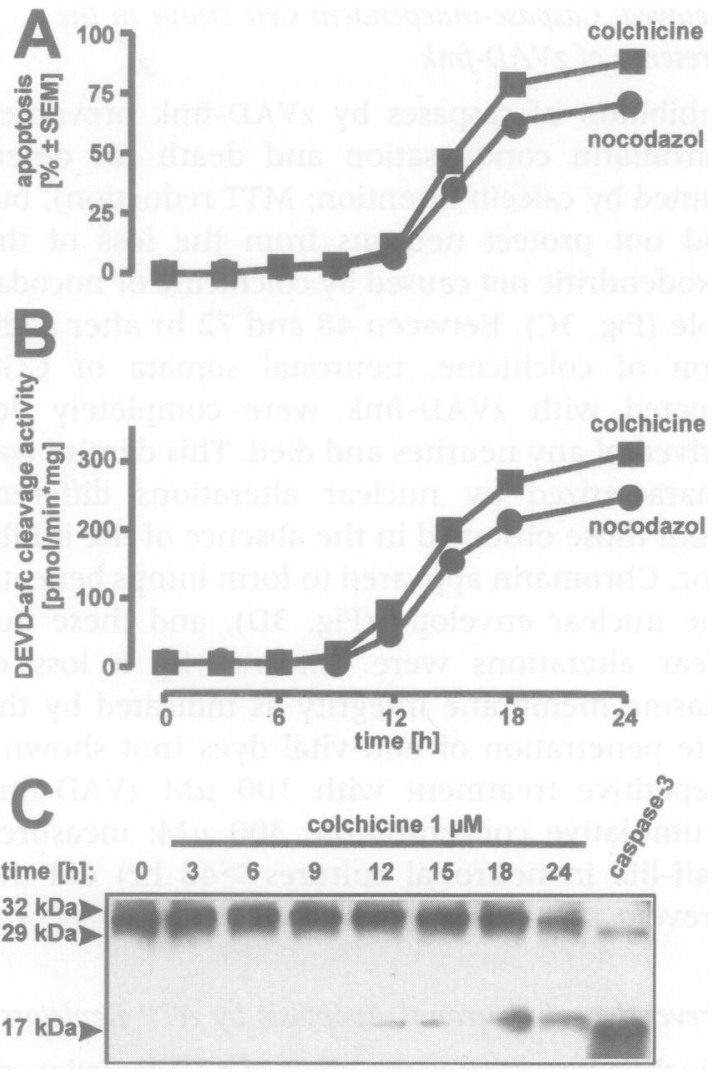

Fig. 1. Time course of caspase activation by microtubule disrupting agents. CGC were incubated with nocodazol $(1 \mu \mathrm{M})$ or colchicine $(1 \mu \mathrm{M})$. At the time points indicated, the percentage of apoptotic nuclei was counted in cultures stained with H-33342 (A). Enzymatic caspase-activity (DEVD-afc cleavage) (B) and processing of procaspase-3 (C) were determined in parallel cultures. Recombinant caspase-3 (20 ng/lane) was used as positive control for Western blotting. Data are means \pm SEM from seven determinations. Error bars are smaller than the data symbols.

$\mathrm{Ca}^{2+}$ channels (10 $\mu \mathrm{M}$ verapamil) or of calcineurin- and cyclophilin-dependent proteins $(2$ $\mu \mathrm{M}$ FK506; $1 \mu \mathrm{M}$ cyclosporine A) had no significant effect on colchicine/nocodazol-triggered caspase activation or on apoptosis. Thus, microtubule breakdown seemed to be the predominant upstream event leading to caspase activation in this model.

\section{Prevention of Apoptosis by Caspase Inhibition}

We investigated the causal role of caspases in apoptosis induced by microtubule disruption by using different irreversible halomethyl ketone caspase inhibitors and the reversible tetrapeptide aldehyde inhibitor DEVD-CHO. All inhibitors known to

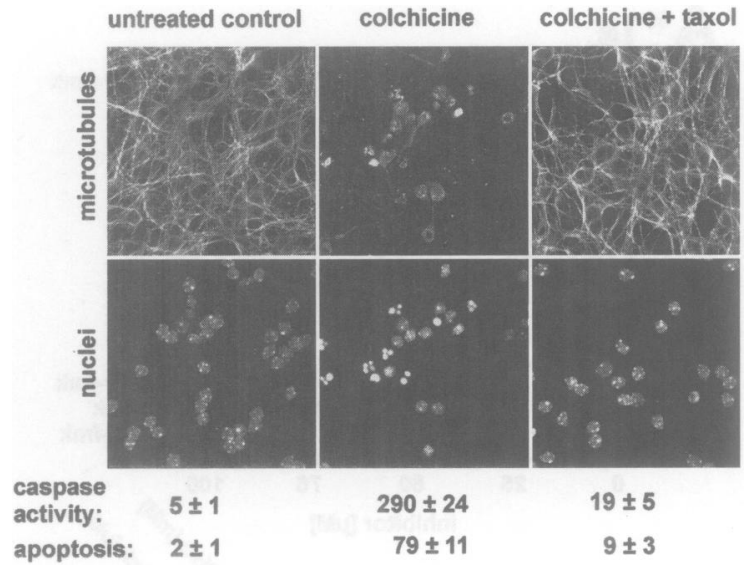

Fig. 2. Prevention of colchicine-induced caspase activation by taxol. CGC were treated with colchicine $(1 \mu \mathrm{M})$ in the presence or absence of taxol $(1 \mu \mathrm{M})$ for $18 \mathrm{hr}$. Parallel cultures were used for quantitating the percentage of apoptotic neurons (condensed chromatin) for measuring caspase activity [DEVD-afc cleavage in $\mathrm{pmol} /(\mathrm{min} \times \mathrm{mg})$ ] and for immunocytochemistry (staining of $\beta$ III-tubulin). Nuclei were stained with $\mathrm{H}-33342$ and correspond to the same field used for imaging the tubulin structure. The images were obtained by confocal microscopy ( $\times 63$, NA 1.4 lens), and the width of every panel corresponds to $100 \mu \mathrm{m}$.

block caspase-3-related caspases protected from colchicine-triggered apoptosis in a concentrationdependent manner (zD-cbk, zVAD-fmk: $\mathrm{IC}_{50}=2$ $\mu \mathrm{M}$; DEVD-fmk: $\mathrm{IC}_{50}=15 \mu \mathrm{M}$; DEVD-CHO: $\mathrm{IC}_{50}=250 \mu \mathrm{M}$; Fig. 3A). Complete protection from apoptosis by $\mathrm{zVAD}$-fmk was still observed when the inhibitor was added up to $10 \mathrm{hr}$ after colchicine. In contrast, YVAD-cmk, which is more specific for caspases related to caspase- 1 , did not prevent apoptosis at concentrations up to $100 \mu \mathrm{M}$ (Fig. 3A).

Caspase activation was also tested by analyzing fodrin proteolysis. Fodrin was cleaved to 150 and $120 \mathrm{kDa}$ fragments after exposure of CGC to colchicine (or nocodazol, not shown), and the proteolysis to the $120 \mathrm{kDa}$ fragment [which is a specific marker for caspase-3 activity (29)] was inhibited by the caspase inhibitors that protected from apoptosis (Fig. 3B). The extent of inhibition of fodrin cleavage with different inhibitors correlated with the protective effect exerted by these agents on apoptosis. This finding further confirms that caspase3-like caspases are the principal executors of neuronal apoptosis induced by microtubule breakdown. 


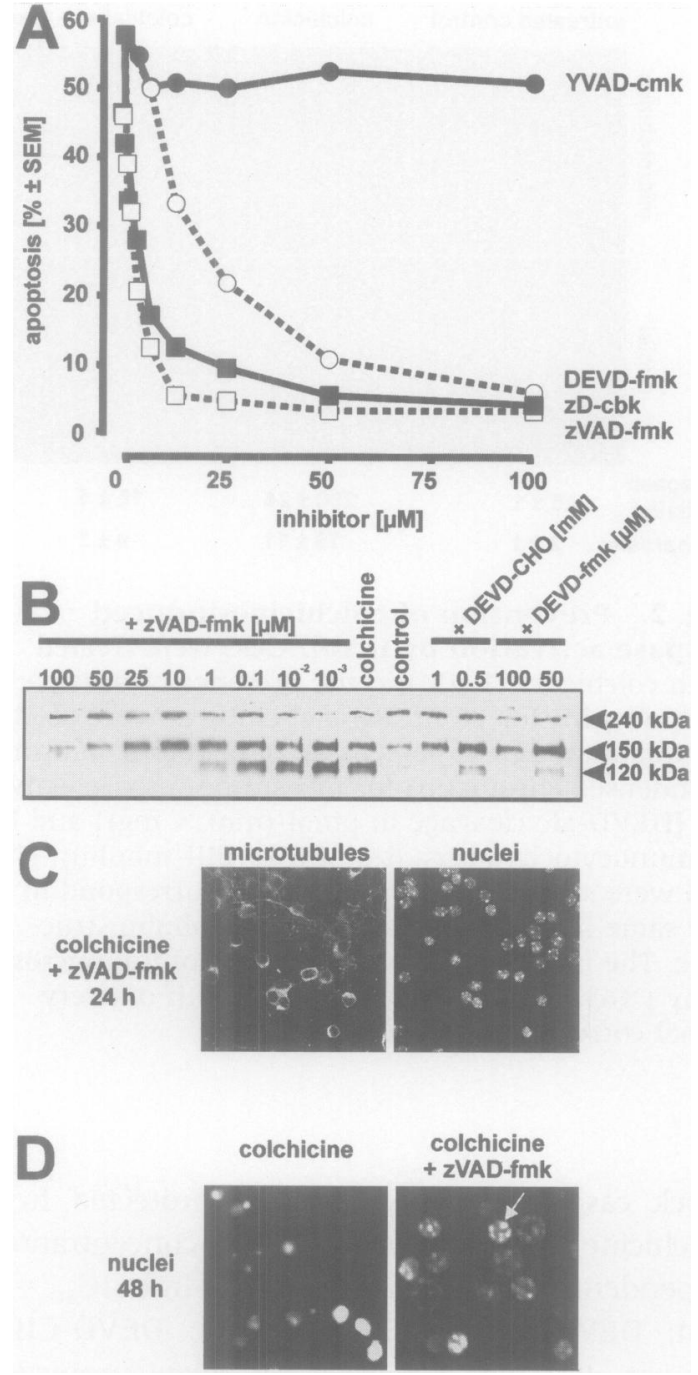

Fig. 3. Inhibition of colchicine-triggered apoptosis by caspase inhibitors. (A) CGC were treated with colchicine $(1 \mu \mathrm{M})$ in the presence or absence of different caspase inhibitors (YVAD-cmk, filled circles; DEVDfmk, open circles; zD-cbk, filled squares; zVAD-fmk, open squares), and the percentage of apoptotic neurons was counted after $16 \mathrm{hr}$. Data are means \pm SEM from triplicate determinations. Essentially similar data were obtained with nocodazol as stimulus. (B) CGC were treated as above in the presence of different caspase inhibitors. At the end of the incubation cell lysates were prepared and analyzed by Western blot for cleavage of fodrin. (C) CGC were incubated for 24 hr with colchicine $(1 \mu \mathrm{M})$ in the presence of zVADfmk (100 $\mu \mathrm{M})$. Tubulin structure and nuclear morphology were imaged by confocal microscopy. The width of one image corresponds to $100 \mu \mathrm{m}$. (D) CGC were incubated for $48 \mathrm{hr}$ with colchicine $(1 \mu \mathrm{M})$ in the presence or absence of zVAD-fmk (100 $\mu \mathrm{M})$. Nuclei were stained with $\mathrm{H}-33342$ and imaged by confocal microscopy. Cells that were treated with zVAD-fmk displayed marginated, but not condensed, chromatin (indicated by the arrow; for comparison apoptotic nuclei of cells that did not receive the caspase inhibitor are also shown). Note the scale difference (the image width corresponds to $25 \mu \mathrm{m}$ ).
Delayed, Caspase-independent Cell Death in the Presence of zVAD-fmk

Inhibition of caspases by zVAD-fmk prevented chromatin condensation and death (as determined by calcein retention; MTT reduction), but did not protect neurons from the loss of the axodendritic net caused by colchicine or nocodazole (Fig. 3C). Between 48 and $72 \mathrm{hr}$ after addition of colchicine, neuronal somata of CGC treated with zVAD-fmk were completely deprived of any neurites and died. This demise was characterized by nuclear alterations different from those observed in the absence of the inhibitor. Chromatin appeared to form lumps beneath the nuclear envelope (Fig. 3D), and these nuclear alterations were followed by a loss of plasma membrane integrity as indicated by the late penetration of non-vital dyes (not shown). Repetitive treatment with $100 \mu \mathrm{M}$ zVAD-fmk (cumulative concentration: $300 \mu \mathrm{M}$; measured half-life in neuronal cultures $>48 \mathrm{hr}$ ) did not prevent this form of cell death.

\section{Prevention of Neuronal Apoptosis by ATP Depletors}

We then investigated the effect of ATP depletion on caspase activity and CGC apoptosis. To avoid secondary excitotoxic effect $(18,22)$, these experiments were all performed in the presence of the NMDA-receptor blocker MK801. When CGC were exposed to the glucose analogue 2-deoxyglucose (DG, 1-3 mM), the intracellular ATP concentration dropped below $50 \%$ within minutes and reached a level of $20 \%$ compared to untreated controls after $1 \mathrm{hr}$; then it further decreased during the following $20 \mathrm{hr}$ (Fig. 4A). This treatment had no effect per se on neuronal viability (calcein uptake, SYTOX exclusion), neuronal morphology (phase contrast), chromatin structure (H-33342 staining), or mitochondrial membrane potential (tetramethylrhodamine methylester uptake) for at least $24 \mathrm{hr}$ [Fig. 4B (22)]. Essentially similar findings were obtained when the two inhibitors of oxidative phosphorylation GSNO or $\mathrm{MPP}^{+}$were used as ATP depletors [Fig. 4B $(22,30)$ ].

Pretreatment of CGC with DG abolished neuronal apoptosis triggered by microtubule disruption (Fig. 4B). Even delayed addition of DG up to $10 \mathrm{hr}$ after colchicine exposure still prevented apoptosis. Thus, ATP-dependent steps were crucial after this time. GSNO and $\mathrm{MPP}^{+}$ also prevented colchicine-induced apoptosis to a similar extent (Fig. 4B).

We tested whether ATP depletion would prevent apoptosis in another paradigm of neuro- 

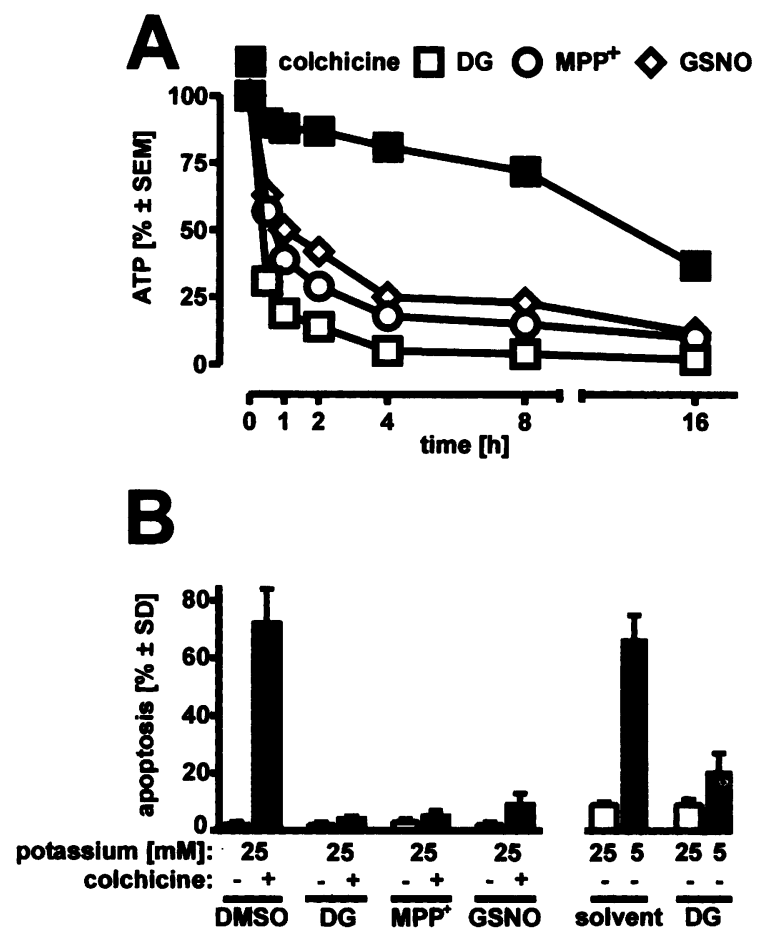

Fig. 4. Prevention of colchicine-triggered apoptosis by ATP depletion. (A) CGC were incubated with deoxyglucose (DG, $2 \mathrm{mM}), \mathrm{MPP}^{+}(50 \mu \mathrm{M})$, GSNO (100 $\mu \mathrm{M})$, or colchicine $(1 \mu \mathrm{M})$, and cellular ATP was measured after the times indicated. ATP content in control neurons was $2.8 \mathrm{nmol} / \mathrm{mg}$ protein, and data are given as percent of untreated control cells. Data are means \pm SEM from quadruplicate measurements. (B) Left: CGC were incubated with colchicine $(0$ or $1 \mu \mathrm{M}$ ) for $24 \mathrm{hr}$ in the continuous presence of DG $(2 \mathrm{mM})$ GSNO $(100 \mu \mathrm{M}), \mathrm{MPP}^{+}(50$ $\mu \mathrm{M})$, or solvent control DMSO (dimethylsulphoxide) in normal culture medium containing $25 \mathrm{mM}$ potassium. Right: medium was exchanged for a controlled salt solution $(27,31)$ containing $0.5 \mathrm{mM}$ glucose and either 5 or $25 \mathrm{mM}$ potassium. In addition, cells were incubated with 0 or $2 \mathrm{mM}$ DG. The percentage of apoptotic neurons was determined after staining with $\mathrm{H}-33342$. Data are means \pm SD from three different experiments.

nal apoptosis. One of the best-characterized models in CGC is withdrawal of potassium (31). In this setup, apoptosis was significantly reduced by deoxyglucose when the salt solution used for the withdrawal situation contained low glucose concentrations $(0.5 \mathrm{mM})$, but not after supplementation with the normally used high glucose concentrations (10 mM) (Fig. 4B).

\section{Restoration of Caspase Activity and Cell Death by} Repletion of Intracellular ATP

The ATP depletion elicited by DG, GSNO, and $\mathrm{MPP}^{+}$was then antagonized by increasing the glucose concentration in the culture medium. Supplementation of the medium with $10 \mathrm{mM}$ glucose bypassed the effects of DG and restored cellular ATP levels as well as colchicine-triggered caspase activity and apoptotic death (Fig. 5A). As a corollary, the prevention of procaspase- 3 processing by DG was also reversed by glucose (Fig. 5B).

Glucose may be metabolized glycolytically to generate ATP. Alternatively, it may be channeled into the pentose-phosphate shunt that provides cells with NADPH and therefore increases their capacity to cope with oxidative stress. To get clarity on the metabolic role of glucose, we also used alternative energy substrates that are not metabolized in the pentosephosphate shunt. All substances that repleted ATP [ $10 \mathrm{mM}$ glycerol $(65 \%), 20 \mathrm{mM}$ succinate $(65 \%), 5 \mathrm{mM}$ glutamine $(60 \%)]$ restored the ability of CGC to undergo apoptosis $(55 \%$, $65 \%, 50 \%$, respectively, compared to restoration with glucose). Nonrepleting substances (creatine, fructose, 1,6-fructose-bisphosphate) had no effect on apoptosis.

Glutathione measurements showed that the cellular content of this redox buffer is not significantly altered by incubation with DG or DG plus colchicine for up to $14 \mathrm{hr}$. This further suggests that DG acts by ATP depletion and not by increasing oxidative stress in neurons. We also found that the capacity of cells to initiate apoptosis is retained in CGC for at least $20 \mathrm{hr}$ after incubation with DG and colchicine: when glucose was added to cultures after that time, apoptosis started immediately, reaching $27 \%$ after $60 \mathrm{~min}$ and $72 \%$ after $4 \mathrm{hr}$. Thus, it seems unlikely that caspases had been inactivated, e.g., by oxidative or nitrative stess.

Since CGC have a very high glycolytic capacity (32), increased glucose concentrations also compensated the ATP depletion affected by the mitochondrial inhibitors $\mathrm{MPP}^{+}$and GSNO. As in the case of DG, caspase activity, caspase-3 processing, and the rate of apoptosis were modulated in parallel (Fig. 6).

When we examined the morphological features of degenerating neurons after exposure to colchicine, we noticed that ATP depletion (Fig. 5C) prevented all the features of neuronal demise, which were also precluded by the caspase inhibitors. The most relevant finding was that treatment with DG prevented colchicinetriggered exposure of phosphatidylserine (PS) on the cell surface, a key factor for recognition of apoptotic cells by phagocytes (5-7). Glucose 

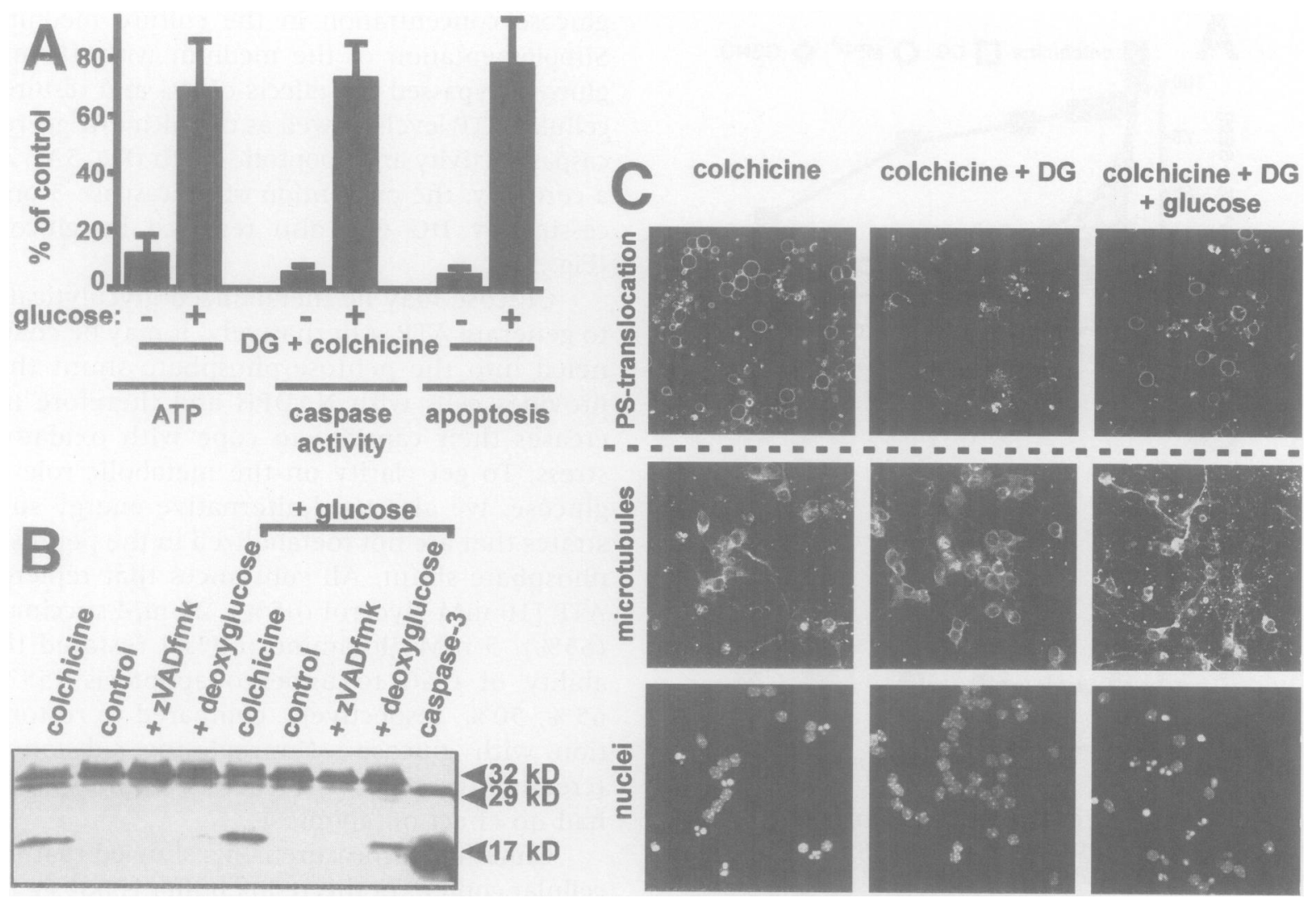

Fig. 5. ATP repletion, colchicine-triggered apoptosis, and caspase activity in DG-treated CGC. (A) Medium of CGC was supplemented with glucose (10 mM) or not. Neurons were then treated with colchicine $(1 \mu \mathrm{M})$. Deoxyglucose (DG, $2 \mathrm{mM}$ ) was added to all cultures $8 \mathrm{hr}$ after colchicine treatment. ATP was measured $9.5 \mathrm{hr}$ after addition of colchicine (1.5 hr after DG); caspase activity and apoptosis were quantitated after $18 \mathrm{hr}$ exposure to colchicine (8.5 hr after DG). As a control, neurons were incubated with colchicine alone. Data from this incubation (see Figs. 1, 4) were used as $100 \%$ reference values. All data shown are expressed as a percentage of colchicine-alone values and are means from three different experiments. (B) CGC were incubated in

clearly reversed the inhibition of apoptotic-related morphological features and the inhibition of PS exposure (Fig. 5C).

\section{Control of Apoptosis by ATP due to Translation-} dependent and Translation-independent Mechanisms

Protein synthesis depends on high ATP concentrations, and colchicine-induced apoptosis may require ongoing translation. We found that both cycloheximide (CHX) and actinomycin D (ActD) prevented caspase activation and apoptotic death. The two inhibitors of protein synthesis arrested the neuronal degeneration process at a the absence or presence of glucose and of different inhibitors as described above. After $18 \mathrm{hr}$, cell lysates were prepared and analyzed by Western blot for caspase- 3 processing. Recombinant caspase- 3 was used as standard. (C) CGC were exposed to colchicine for $18 \mathrm{hr}$ either directly in the presence of DG, or in the presence of DG plus glucose. Phosphatidylserine (PS) translocation was stained in live neurons with annexin $\mathrm{V}$ and imaged by confocal microscopy. Plasma membranes of $>\mathbf{9 0} \%$ of all neurons were impermeable to ethidiumhomodimer at that time point. Microtubules and chromatin structure were examined in parallel cultures after fixation and staining with anti- $\beta$ III-tubulin and H-33342.

morphological stage similar to that observed with DG or zVAD-fmk (Fig. 7A). Pronounced protection from apoptosis by delayed addition of $\mathrm{CHX}$ was observed up to about $10 \mathrm{hr}$ after colchicine addition. As shown in Figure 7B, the time point beyond which neurons could not be rescued from apoptosis by CHX treatment was similar to that observed for caspase inhibition and for ATPdependent steps.

In view of these findings, we considered that ATP depletion may prevent apoptosis, at least in part, by a block of translation. To test this possibility, we measured the inhibitory effect on translation of different concentrations of DG or 


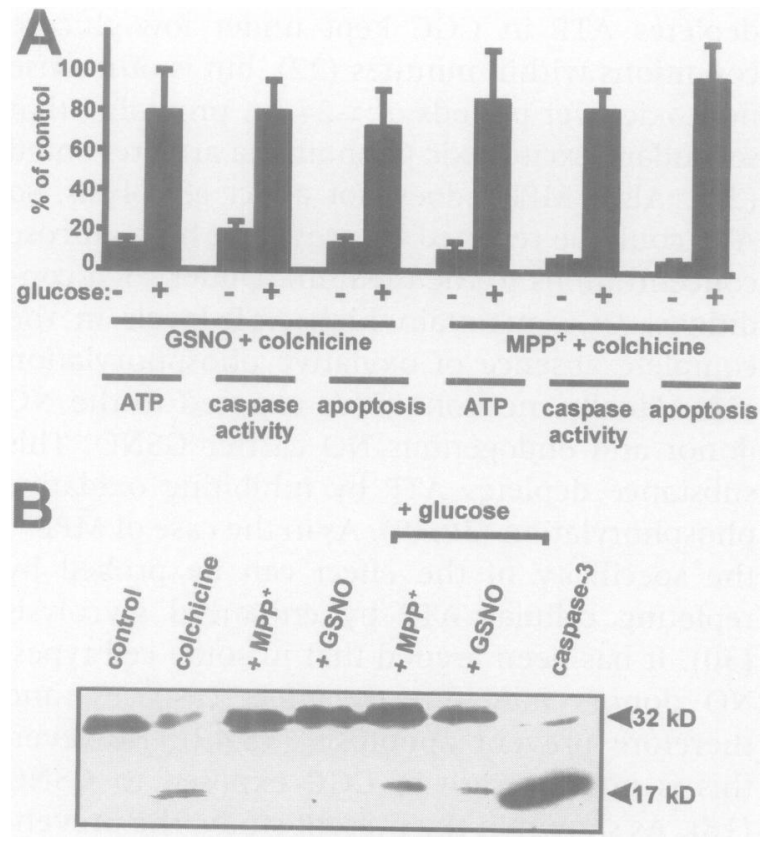

Fig. 6. ATP repletion, colchicine-triggered apoptosis, and caspase activity in CGC treated with GSNO or MPP ${ }^{+}$. (A) Medium of CGC was supplemented with glucose $(10 \mathrm{mM})$ or not. Neurons were then treated with colchicine $(1 \mu \mathrm{M})$. GSNO $(100 \mu \mathrm{M})$ or $\mathrm{MPP}^{+}(50 \mu \mathrm{M})$ was added to the cultures $8 \mathrm{hr}$ after colchicine. ATP was measured 9.5 $\mathrm{hr}$ after addition of colchicine (1.5 hr after $\mathrm{MPP}^{+}$, GSNO); caspase activity and apoptosis were quantitated after $18 \mathrm{hr}$ exposure to colchicine $(8.5 \mathrm{hr}$ after $\mathrm{MPP}^{+} / \mathrm{GSNO}$ ). As a control, neurons were incubated with colchicine alone. Data from this incubation (see Fig. 4) were used as $100 \%$ reference values. All data shown are expressed as percentage of colchicinealone values and are means from three different experiments. (B) CGC were incubated in the absence or presence of glucose and of different inhibitors as described above. After $18 \mathrm{hr}$, cell lysates were prepared and analyzed by Western blot for caspase- 3 processing. Recombinant caspase- 3 was used as standard.

CHX. The resulting data were compared with the corresponding concentration of either inhibitor required to prevent colchicine-triggered apoptosis (Fig. 7C). High DG concentrations ( $\geq 5 \mathrm{mM}$ ) were able to completely shut down protein synthesis, and may thus have inhibited apoptosis exclusively by this mechanism. On the other hand, low DG concentrations ( $\leq 1 \mathrm{mM}$ ) inhibited apoptosis, although inhibition of translation was minimal $(<25 \%)$. Such a small extent of translational inhibition did not prevent apoptosis when CHX was used instead. Thus, ATP depletion by DG blocked apoptosis and caspase àctivation by an additional mechanism unrelated to the inhibition of translation.
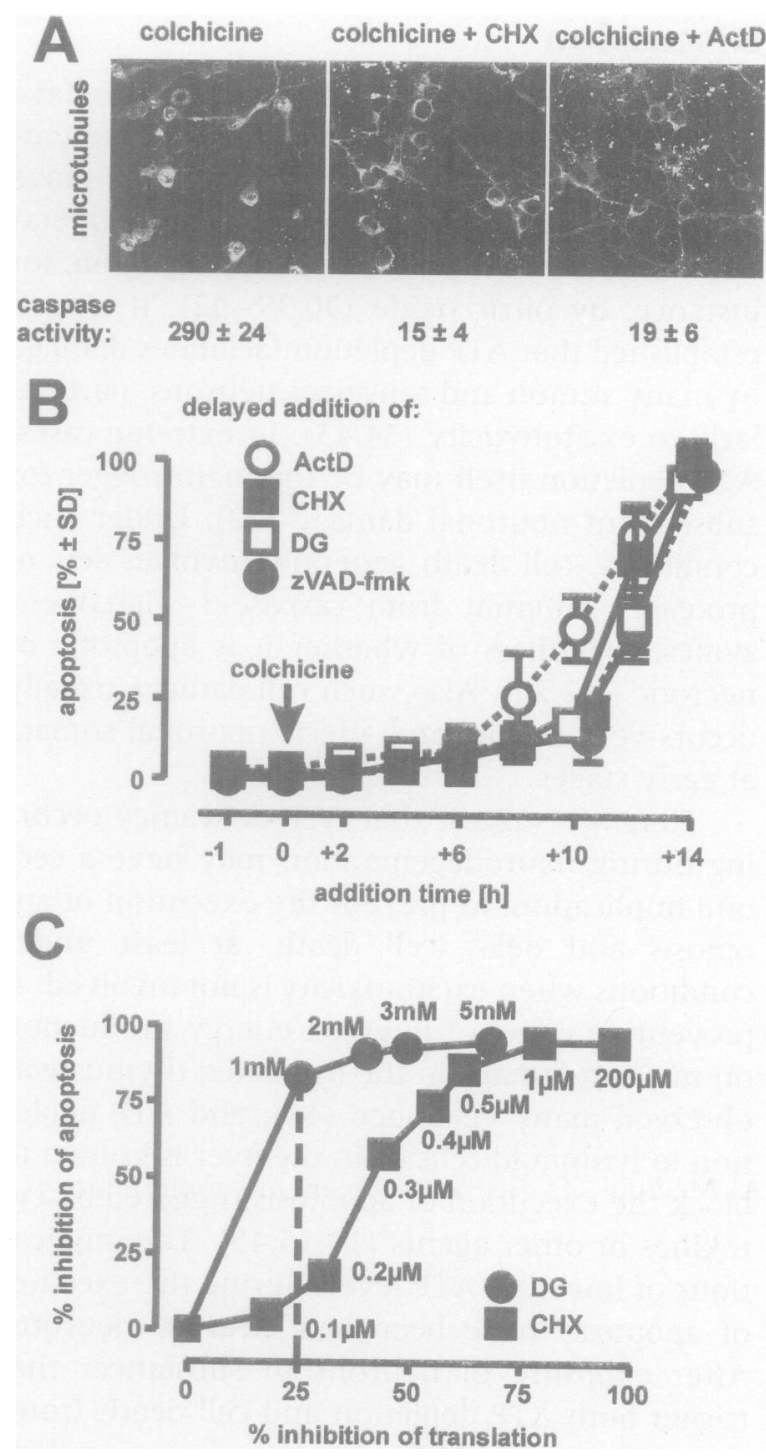

Fig. 7. Apoptosis prevention and translational block: a comparison of $\mathrm{CHX}$ and DG effects. (A) CGC were exposed to colchicine for $18 \mathrm{hr}$ in the presence or absence of $\mathrm{CHX}(1 \mu \mathrm{M})$ or ActD (150 $\mathrm{nM}$ ) until caspase activity (pmol/(min $\times \mathrm{mg}$ ) was determined enzymatically and tubulin structure was examined by immunostaining. (B) Different inhibitors ( $2 \mathrm{mM}$ DG, $1 \mu \mathrm{M} \mathrm{CHX}, 100 \mu \mathrm{M}$ zVAD-fmk, 150 nM ActD) were added to CGC cultures either l hr before colchicine $(-1)$ or at different times after colchicine as indicated on the ordinate. All experiments were stopped $18 \mathrm{hr}$ after colchicine addition. Data are presented as percent of the apoptosis, observed with colchicine alone. Experiments were performed 3-4 times and averages of all experimental data are shown. (C) CGC were incubated with different concentrations of $\mathrm{CHX}$ or DG at $8 \mathrm{hr}$ after exposure to colchicine $(1 \mu \mathrm{M})$. Inhibition of translation by DG or CHX was measured in the period of 90-180 min after their addition; inhibition of apoptosis was measured $9 \mathrm{hr}$ later. The different inhibitor concentrations are indicated in the figure. Data are averages of three experiments. 


\section{Discussion}

Defects in mitochondrial energy generation have been frequently associated with neurodegenerative diseases (33-36). Such defects may have either a genetic basis $(37,38)$ or be due to metabolic inhibition of oxidative phosphorylation, for instance, by nitric oxide $(30,39-42)$. It is well established that ATP depletion facilitates damage by many stimuli and sensitizes neurons, particularly to excitotoxicity $(34,43)$. In extreme cases, ATP depletion itself may be the main trigger for subsequent neuronal damage (22). Under such conditions, cell death generally involves sets of proteases different from caspase-3-related enzymes, regardless of whether it is apoptotic or necrotic $(1,2,22)$. Also, such cell damage usually occurs very rapidly and affects neuronal somata at early stages.

Here we suggest that ATP deficiency occuring during neurodegeneration may have a second implication: to prevent the execution of apoptosis and delay cell death, at least under conditions when excitotoxicity is not involved. A preventive effect of lowered energy production on nuclear damage in the irradiated thymus was observed many years ago (44), and ATP depletion in lymphoid cells or in the liver is known to block the execution of apoptosis triggered by cytokines or other agents $(14,15,45)$. The implications of lowering ATP levels during the exection of apoptosis have been less clear in neurons. After exposure of neurons to substances that trigger both ATP depletion and cell death (rotenone, glutamate, $\mathrm{MPP}^{+}$), apoptosis is prevalent under conditions of relatively minor ATP loss, whereas necrosis occurs when the ATP loss is more severe $(1,17)$. In the present study, apoptosis and the associated caspase activation were triggered by agents that themselves have only minor effects on energy generation or consumption. Thus, ATP levels could be modulated independently from the pro-apoptotic stimuli. We used three different ATP depletors, which did not compromise neuronal viability. The first was deoxyglucose, which competes with glucose for both cellular uptake and glycolytic metabolism. This can be considered a model for reduced glycolytic flux in neurons and it offers the additional advantage of easy reversibility of the effect of deoxyglucose by increasing glucose supply to the neurons. The second ATP depletor, $\mathrm{MPP}^{+}$, is a model toxin for the induction of Parkinson's disease (46) and it was used here as a selective inhibitor of mitochondrial complex I (47). $\mathrm{MPP}^{+}$ depletes ATP in CGC kept under low-glucose conditions within minutes (22), but is otherwise nontoxic over periods of $\leq 24 \mathrm{hr}$, providing that secondary excitotoxic phenomena are prevented (22). Also, $\mathrm{MPP}^{+}$does not affect glycolysis, so ATP could be repleted by providing high glucose concentrations to the medium. Under such conditions, CGC maintain high ATP levels in the complete absence of oxidative phosphorylation (32). Finally, neurons were exposed to the NO donor and endogenous NO carrier GSNO. This substance depletes ATP by inhibiting oxidative phosphorylation $(30,39)$. As in the case of $\mathrm{MPP}^{+}$, the specificity of the effect can be probed by repleting cellular ATP by enhanced glycolysis (30). It has been argued that in some cell types, NO donors may directly affect caspases, and therefore prevent apoptosis $(48,49)$. However, this is not the case in CGC exposed to GSNO (18). As shown in the present study, the prevention of caspase activation and apoptosis by NO donors can be explained by their ability to deplete ATP, since the effects of GSNO on apoptosis were easily reversed by glucose.

The execution of several, currently known apoptotic degradation processes can procede in the absence of ATP. For instance, nuclear condensation, PS exposure, protease activities, and DNAse activities themselves do not require energy. However, one central step upstream of these activities is the activation of execution caspases within the so-called apoptosome complex. In vitro, reconstitution of this complex is only possible in the presence of ATP or dATP $(12,13)$, and depletion of ATP by $50-70 \%$ in living cells prevents caspase activation $(14,15,30)$. Conversely, glucose supplementation restores caspase activation and the apoptotic phenotype. Thus, inhibition of caspase activation at the level of the apoptosome is a plausible mechanism, which can explain the effects of ATP depletion observed in our system. Accordingly, we found that procaspases- 3 and 7 were not processed in ATP-depleted neurons.

In addition to the apoptosome complex, a second target that is influenced by ATP depletion involves translation-dependent processes. In several nonexcitotoxic models of programmed neuronal death [e.g., growth factor withdrawal, potassium deprivation $(50,51)$, caspase activation and apoptosis are prevented by inhibitors of protein synthesis. Here we showed that colchicineor nocodazol-induced apoptosis is also sensitive to agents or conditions that inhibit protein synthesis. High concentrations of DG or $\mathrm{MPP}^{+}$de- 
pleted ATP by $>90 \%$, and shut down protein synthesis by $\geq 95 \%$. However, lower concentrations of deoxyglucose, which depleted ATP to a lesser extent and hardly caused any inhibition of protein synthesis $(<25 \%)$, still prevented caspase activation. Thus, ATP depletion may affect neuronal apoptosis indirectly due to inhibition of protein synthesis and directly due to its effect at the level of caspase processing by the apoptosome.

Intraventricular colchicine injection in the brain is a well-characterized inducer of neuronal stress (52) and stress responses (53). In addition to microtubule depolymerization and cell cycle arrest, colchicine triggers apoptosis in many tumor cells (54) as well as in postmitotic CGC in vitro $(18,20)$ and in vivo $(19)$. Exposure of CGC to colchicine has several secondary effects, such as induction of NO synthase, fos-expression, and disturbance of $\mathrm{Ca}^{2+}$ homeostasis, all of which precede typical apoptotic processes, such as DNA fragmentation, activation of caspases, and cleavage of fodrin $(20,18,22)$. Our present findings show that caspase activation and the subsequent apoptotic events are strictly dependent on microtubule depolymerization itself. This is suggested by the comparable effects of colchicine and nocodazol, which are chemically unrelated but cause microtubule disruption. In addition, block of microtubule depolymerization by taxol, which functionally antagonizes colchicine, prevented caspase activation and apoptosis. This confirms earlier suggestions that microtubule integrity may indeed be one of the general sensors important for the control of the cell death machinery $(20,55)$. Recent data showing an effect of microtubule disruption on mitochondrial permeability transition (56) and on the phosphorylation state of Bcl-2 $(55,57)$ suggest a link between microtubule integrity and suppression of caspase-activating mechanisms.

Although caspase inhibitors did not prevent microtubule breakdown and the loss of neuronal projections, the somata remained viable (as analyzed by MTT reduction, leucine incorporation, and calcein retention) for $\geq 36 \mathrm{hr}$. Thereafter, neurons started to die slowly with features that differed morphologically from those of classical apotosis. These cells, while undergoing some kind of nuclear condensation and chromatin margination (as observed in pre-apoptotic stages), did not expose phosphatidylserine on the outer surface (data not shown) and underwent late cell lysis. This is consistent with previous observations that caspase inhibition can block apoptosis, but not entirely pre- vent delayed cell death $(14,30,58,59)$. Thus, our findings suggest that inhibition of caspases can explain the uncoupling of degenerative processes in neuronal projections from the eventual death of the cell. In particular, the observation that caspase inhibition hinders PS exposure but does not prevent late cell lysis raises the question as to whether pharmacological inhibition of caspases is always desirable in in vivo neurodegenerative conditions. Inhibition of caspases by synthetic peptides, as well as prevention of caspase activation because of a concomitant energy deprivation, would allow the persistence and late dissolution of severely damaged cells (57). Such conditions may foster the onset of inflammatory responses and a progression of disease.

\section{Acknowledgments}

The excellent technical assistance of $\mathrm{H}$. Naumann and T. Schmitz is gratefully acknowledged. We are grateful to Dr. D. W. Nicholson (Merck Frost Center for Therapeutic Research, Quebec, Canada) for providing the anti-caspase-3 antibodies, to Dr. F. Fackelmayer (Konstanz, Germany) for providing caspase-3, and to Dr. G. Cohen (MRC Toxicology, Leicester, UK) for providing caspase-7 antibody. This study was supported by the Land Baden-Württemberg and DFG grants We686/18-1, Ni519/1-1, Ni519/2-1 and the EEC grants BMH4CT97-2410 and 12029-97-06 F1ED ISP D.

\section{References}

1. Leist M, Nicotera P. (1998) Apoptosis, excitotoxicity, and neuropathology. Exp. Cell Res. 239: 183201.

2. Nicotera P, Leist M, Manzo L. (1999) Neuronal cell death: a demise with different shapes. Trends Pharmacol. Sci. 20: 46-51.

3. Stroh C, Schulze-Osthoff K. (1998) Death by a thousand cuts: an ever increasing list of caspase substrates. Cell Death Differ. 5: 997-1000.

4. Wyllie AH, Kerr JF, Currie AR. (1980) Cell death: the significance of apoptosis. Int. Rev. Cytol. 68: 251-306.

5. Krahling S, Callahan MK, Williamson P, Schlegel RA. (1999) Exposure of phosphatidyl-serine is a general feature in the phagocytosis of apoptotic lymphocytes by macrophages. Cell Death Differ. 6: 183-189.

6. Ren Y, Savill J. (1998) Apoptosis: the importance of being eaten. Cell Death Differ. 5: 563-568. 
7. Savill J, Fadok V, Henson P, Haslett C. (1993) Phagocyte recognition of cells undergoing apoptosis. Immunol. Today 14: 131-136.

8. Stadelmann C, Brück W, Bancher C, Jellinger K, Lassmann H. (1998) Alzheimer disease: DNA fragmentation indicates increased neuronal vulnerability, but not apoptotis. J. Neuropathol. Exp. Neurol. 57: 456-464.

9. Barinaga M. (1998) Is apoptosis key in Alzheimer's disease? Science 281: 1303-1304.

10. Hsia AY, Masliah E, McConlogue L, et al. (1999) Plaque-independent disruption of neural circuits in Alzheimer's disease mouse models. Proc. Natl. Acad. Sci. U.S.A. 96: 3228-3233.

11. Braak H, Braak E. (1998) Cortical destruction and cell death in Alzheimer's disease. In: Koliatsos VE, Ratan RR (eds). Cell Death and Diseases of the Nervous System. Humana Press, Totowa, NJ, pp 497-510.

12. Li P, Nijhawan D, Budihardjo I, et al. (1997) Cytochrome $c$ and dATP-dependent formation of Apaf-1/Caspase-9 complex initiates an apoptotic protease cascade. Cell 91: 479-489.

13. Liu X, Kim CN, Yang J, Jemmerson R, Wang X. (1996) Induction of apoptotic program in cell-free extracts: requirement for dATP and cytochrome c. Cell 86: 147-157.

14. Leist $M$, Single B, Castoldi AF, Kühnle S, Nicotera P. (1997) Intracellular ATP concentration: a switch deciding between apoptosis and necrosis. $J$. Exp. Med. 185: 1481-1486.

15. Eguchi Y, Shimizu S, Tsujimoto Y. (1997) Intracellular ATP levels determine cell death fate by apoptosis or necrosis. Cancer Res. 57: 1835-1840.

16. Ankarcrona M, Dypbukt JM, Bonfoco E, et al. (1995) Glutamate-induced neuronal death: a succession of necrosis or apoptosis depending on mitochondrial function. Neuron 15: 961-973.

17. Hartley A, Stone JM, Heron C, Cooper JM, Schapira AHV. (1994) Complex I inhibitors induce dose-dependent apoptosis in PC12 cells: relevance to Parkinson's disease. J. Neurochem. 63: 19871990.

18. Leist $M$, Volbracht $C$, Kühnle S, Fava E, FerrandoMay E, Nicotera P. (1997) Caspase-mediated apoptosis in neuronal excitotoxicity triggered by nitric oxide. Mol. Med. 3: 750-764.

19. Ceccatelli S, Ahlbom E, Diana A, Zhivotovsky B. (1997) Apoptosis in rat hippocampal dentate gyrus after intraventricular colchicine. Neuroreport 8: 3779-3783.

20. Bonfoco E, Ceccatelli S, Manzo L, Nicotera P. (1995) Colchicine induces apoptosis in cerebellar granule cells. Exp. Cell Res. 218: 189-200.

21. Schousboe A, Meier E, Drejer J, Hertz L. (1989) Preparation of primary cultures of mouse (rat) cerebellar granule cells. In: Shahar A, de Vellis J, Vernadakis A, Haber B (eds). A Dissection and Tissue Culture Manual of the Nervous System. Alan R. Liss, New York, pp 203-206.
22. Leist M, Volbracht C, Fava E, Nicotera P. (1998) 1-methyl-4-phenylpyridinium $\left(\mathrm{MPP}^{+}\right)$induces autocrine excitotoxicity, protease activation and neuronal apoptosis. Mol. Pharmacol. 54: 789-801.

23. Leist M, Fava E, Montecucco C, Nicotera P. (1997) Peroxynitrite and NO-donors induce neuronal apoptosis by eliciting autocrine excitotoxicity. Eur. J. Neurosci. 9: 1488-1498.

24. Leist M, Kühnle S, Single B, Nicotera P. (1998) Differentiation between apoptotic and necrotic cell death by means of the BM cell death detection ELISA or annexin V staining. Biochemica 2: 25-28.

25. Leist M, Gantner F, Bohlinger I, German PG, Tiegs G, Wendel A. (1994) Murine hepatocyte apoptosis induced in vitro and in vivo by TNF-alpha requires transcriptional arrest. J. Immunol. 153: 1778-1787.

26. Thornberry NA. (1994) Interleukin-1 beta converting enzyme. Methods Enzymol. 244: 615-631.

27. Leist M, Single B, Künstle G, Volbracht C, Hentze H, Nicotera P. (1997) Apoptosis in the absence of poly-(ADP-ribose) polymerase. Biochem. Biophys. Res. Commun. 233: 518-522.

28. Tietze F. (1969) Enzymatic method for quantitative determination of nanogram amounts of total and oxidized glutathione: application to mammalian blood and other tissues. Anal. Biochem. 27: 502-522.

29. Jänicke RU, Ng P, Sprengart ML, Porter AG. (1998) Caspase-3 is required for alpha-fodrin cleavage but dispensable for cleavage of other death substrates in apoptosis. J. Biol. Chem. 273: 15540-15545.

30. Leist $M$, Single B, Naumann H, et al. (1999) Nitric oxide inhibits execution of apoptosis at two distinct ATP-dependent steps upstream and downstream of mitochondrial cytochrome c release. Biochem. Biophys. Res. Commun. 258: 215-221.

31. Schulz JB, Weller M, Klockgether T. (1996) Potassium deprivation-induced apoptosis of cerebellar granule neurons: a sequential requirement for new mRNA and protein synthesis, ICE-like protease activity, and reactive oxygen species. $\mathrm{J}$. Neurosci. 16: 4696-4706.

32. Budd SL, Nicholls DG. (1996) A reevaluation of the role of mitochondria in neuronal $\mathrm{Ca}^{2+}$ homeostasis. J. Neurochem. 66: 403-411.

33. Beal MF. (1996) Mitochondria, free radicals, and neurodegeneration. Curr. Opin. Neurobiol. 6: 661666.

34. Mattson MP. (1997) Mother's legacy: mitochondrial DNA mutations and Alzheimer's disease. Trends Neurosci. 20: 373-375.

35. Blandini F, Higgins DSJ, Greene JG, Greenamyre JT. (1997) Glutamate and mitochondrial defects in neurodegeneration. In: Beal MF, Howell $\mathrm{N}$, Bodis-Wollner I (eds). Mitochondria and Free Radicals in Neurodegenerative Diseases. WileyLiss, New York, pp 145-158.

36. Bolanos JP, Almeida A, Stewart V, et al. (1997) Nitric oxide-mediated mitochondrial damage in 
the brain: mechanisms and implications for neurodegenerative diseases. $J$. Neurochem. 68: 22272240.

37. Wallace DC, Lott MT, Brown MD. (1997) Mitochondrial defects in neurodegenerative diseases and aging. In: Beal MF, Howell N, Bodis-Wollner I (eds). Mitochondria and Free Radicals in Neurodegenerative Diseases. Wiley-Liss, New York, pp 283-307.

38. Wallace DC. (1999) Mitochondrial diseases in man and mouse. Science 283: 1482-1488.

39. Leist $M$, Single B, Naumann H, et al. (1999) Inhibition of mitochondrial ATP generation by nitric oxide switches apoptosis to necrosis. Exp. Cell Res. 249: 396-403.

40. Clementi E, Brown GC, Feelisch M, Moncada S. (1998) Persistent inhibition of cell respiration by nitric oxide: crucial role of $S$-nitrosylation of mitochondria complex I and protective action of glutathione. Proc. Natl. Acad. Sci. U.S.A. 95: 76317636.

41. Cleeter MWJ, Cooper JM, Darley-Usmar VM, Moncada S, Schapira AHV. (1994) Reversible inhibition of cytochrome c oxidase, the terminal enzyme of the mitochondrial respiratory chain, by nitric oxide. Implications for neurodegenerative disease. FEBS Lett. 345: 50-54.

42. Schweizer M, Richter C. (1994) Nitric oxide potently and reversibly deenergizes mitochondria at low oxygen tension. Biochem. Biophys. Res. Commun. 204: 169-175.

43. Henneberry RC. (1997) Excitotoxicity as a consequence of impairment of energy metabolism: the energy-linked excitotoxic hypothesis. In: Beal MF, Howell N, Bodis-Wollner I (eds). Mitochondria and Free Radicals in Neurogenerative Diseases. Wiley-Liss, New York, pp 111-143.

44. Whitfield JF, Brohee H. (1966) Prevention of nuclear damage in irradiated rat thymocytes by postirradiation oxygen deprivation. Nature 211: 775776.

45. Leist M, Gantner F, Künstle G, Wendel A. (1998) Cytokine-mediated hepatic apoptosis. Rev. Physiol. Biochem. Pharmacol. 133: 109-155.

46. Tipton KF, Singer TP. (1993) Advances in our understanding of the mechanisms of the neurotoxicity of MPTP and related compounds. J. Neurochem. 61: 1191-1206.

47. Nicklas WJ, Vyas I, Heikkila RE. (1985) Inhibition of NADH-linked oxidation in brain mitochondria by 1-methyl-4-phenyl-pyridine, a metabolite of the neurotoxin, 1-methyl-4-phenyl-1,2,5,6-tetrahydropyridine. Life Sci. 36: 2503-2508.

48. Dimmeler S, Zeiher AM. (1997) Nitric oxide and apoptosis: another paradigm for the double-edged role of nitric oxide. Nitric Oxide 1: 275-281.
49. Tenneti L, D'Emilia DM, Lipton SA. (1997) Suppression of neuronal apoptosis by $S$-nitrosylation of caspases. Neurosci. Lett. 236: 139-142.

50. Kharlamov E, Cagnoli CM, Atabay C, Ikonomovic S, Grayson DR, Manev H. (1995) Opposite effect of protein synthesis inhibitors on potassium deficiency-induced apoptotic cell death in immature and mature neuronal cultures. J. Neurochem. 65: 1395-1398.

51. Martin DP, Schmidt RE, DiStefano PS, Lowry OH, Carter JG, Johnson EM. (1988) Inhibitors of protein synthesis and RNA synthesis prevent neuronal death caused by nerve growth factor deprivation. J. Cell Biol. 106: 829-844.

52. Ceccatelli S, Villar MJ, Goldstein M, Hökfelt T. (1989) Expression of c-fos immunoreactivity in transmitter-characterized neurons after stress. Proc. Natl. Acad. Sci. U.S.A. 86: 9569-9573.

53. Ceccatelli S, Ernfors $P$, Villar MJ, Persson H, Hökfelt T. (1991) Expanded distribution of mRNA for nerve growth factor, brain-derived neurotrophic factor, and neurotrophin 3 in the rat brain after colchicine treatment. Proc. Natl. Acad. Sci. U.S.A. 88: 10352-10356.

54. Martin SJ, Lennon SV, Bonham AM, Cotter TG. (1990) Induction of apoptosis (programmed cell death) in human leukemic HL-60 cells by inhibition of RNA or protein synthesis. J. Immunol. 145: 1859-1867.

55. Srivastava RK, Srivastava AR, Korsmeyer SJ, Nesterova M, Cho-Chung YS, Longo DL. (1998) Involvement of microtubules in the regulation of $\mathrm{Bcl} 2$ phosphorylation and apoptosis through cyclic AMP-dependent protein kinase. Mol. Cell Biol. 18: 3509-3517.

56. Evtodienko YV, Teplova VV, Sidash SS, Ichas F, Mazat JP. (1996) Microtubule-active drugs suppress the closure of the permeability transition pore in tumor mitochondria. FEBS Lett. 393: 8688.

57. Basu A, Haldar S. (1998) Microtubule-damaging drugs triggered Bcl2 phosphorylation-requirement of phosphorylation on both serine-70 and serine-87 residues of $\mathrm{Bcl} 2$ protein. Int. J. Oncol. 13: 659-664.

58. Hirsch T, Marchetti P, Susin SA, et al. (1997) The apoptosis-necrosis paradox. Apoptogenic proteases activated after mitochondrial permeability transition determine the mode of cell death. Oncogene 15: 1573-1581.

59. Green D, Kroemer G. (1998) The central executioners of apoptosis: caspases or mitochondria? Trends Cell Biol. 8: 267-271. 